\title{
IMPACTOS DA MODERNIZAÇÃO SOBRE AS ESTRUTURAS SOCIAIS: 0 EXEMPLO DOS PECUARISTAS DE POCONÉ-MT ${ }^{1}$
}

\author{
Impact of Modernization on Social Structures: The Example of Cattlemen in Poconé-MT
}

\author{
André Luís Ribeiro Lacerda² \\ João Vicente R. B. da Costa Lima ${ }^{3}$
}

\begin{abstract}
Resumo: Este trabalho parte da constatação de um processo social de transformação, identificado na estrutura do status ocupacional de pecuarista pantaneiro, a partir de entrevistas de surveys realizadas entre 2014 e 2015 com pecuaristas pantaneiros que têm propriedades no município de Poconé-MT. Considerando o status ocupacional como variável dependente, identificamos algumas variáveis familiares ao que a literatura sociológica chama de teoria da modernização e que consideramos potenciais variáveis independentes. A hipótese de que o impacto da modernização nas estruturas sociais parece uma boa explicação para as transformações na estrutura ocupacional de pecuarista pantaneiro é defendida a partir do que os trabalhos empíricos sociológicos chamam de padrões de movimento nas estruturas ocupacionais de maneira geral e da relação entre o background dos fazendeiros e o processo de estratificação social.
\end{abstract}

Palavras-Chave: status sócio ocupacional; pecuaristas; modernização.

Abstract: This study starts from the verification of a social transformation process, identified in the structure of occupational status of Pantanal cattlemen and based on survey interviews conducted with Pantanal cattlemen who own properties in the district of Poconé-MT between 2014 and 2015. Considering the occupational status as a dependent variable, we identified some variables that are related to what sociological literature denominates as theory of modernization and we have considered as potential independent variables. The hypothesis according to which the impact of modernization on social structures seems to be a fair explanation for the changes in the occupational status of Pantanal cattlemen is defended on the basis of what empirical sociological studies denominate as movement patterns in occupational structures in general and the relationship between farmers' background and the process of social stratification.

Keywords: sócio-occupational status; cattlemen; modernization.

JEL: A14.

\section{INTRODUÇÃO}

Surveys aplicados em 2014 e 2015 nos pecuaristas pantaneiros que têm propriedades no município de Poconé-MT revelaram diferenças significativas entre as situações socioeconômicas da velha e da nova geração de pecuaristas pantaneiros. Essas diferenças implicam mudanças na estrutura social que se

\footnotetext{
${ }^{1}$ Esta pesquisa é financiada pelo Ministério da Ciência e Tecnologia e administrada pelo Centro de Pesquisa do Pantanal (CPP).

${ }^{2}$ Sociólogo e Psicólogo. Doutor em Sociologia pela UnB. Professor do Departamento de Sociologia e Ciência Política da UFMT, Campus Cuiabá. E-mail: ribeirolacerda66@gmail.com

${ }^{3}$ Sociólogo. Doutor em Sociologia. Professor da UFAL, Campus Maceió. jvcostalima@gmail.com
} 
desenha a partir do status e no próprio status ocupacional de pecuarista pantaneiro.

Encarado como uma variável dependente, o status de pecuarista pantaneiro experimenta transformações assim como os outros status sociais do conjunto de status a que pertence o pecuarista pantaneiro que reside em Poconé-MT (TURNER, 2000). O que explica esta mudança? Identificamos algumas variáveis familiares ao que a literatura sociológica chama de teoria da modernização e que consideramos potenciais variáveis independentes. A hipótese de que o impacto da modernização nas estruturas sociais parece uma boa explicação para as transformações na estrutura ocupacional de pecuarista pantaneiro é defendida a partir do que os trabalhos empíricos sociológicos chamam de padrões de movimento nas estruturas ocupacionais de maneira geral e da relação entre o background dos fazendeiros e o processo de estratificação social.

O impacto da modernização sobre a estrutura social formada a partir do conjunto de statuses de pecuaristas pantaneiros pode ser visto como uma dinâmica de mudança social. Gehard Lenski afirma que a história humana não é apenas uma sequência, "uma teia confusa de eventos sem qualquer padrão ou tendência significativa", mas, ao contrário, apresentava um padrão em que "a presença de tendência de longo prazo é clara e evidente" (LENSKI, 1976, p.554). E segundo ele, a tendência mais evidente é o avanço tecnológico. Ela imprime a direção preponderante da mudança apesar de casos excepcionais de "tecnostase" e "regressão" (SZTOMPKA, 1998, p. 209).

Para Lenski, é possível dizer que todos os demais aspectos da vida social estão fortemente ligados ao caráter da tecnologia, ou seja, as resoluções de uma sociedade para seus problemas tecnológicos " funcionam como um conjunto de condições determinantes do alcance das soluções que a sociedade pode aplicar a outros problemas (LENSKI \& LENSKI,1974, p. 80).

O curso principal da determinação segue a sequência tecnologiaeconomia-sociedade organizada-sistema distributivo (LENSKI, 1966). Mas, Lenski entende a determinação tecnológica como probabilística, por intermédio de um mecanismo que fornece feedback de outros aspectos da sociedade à tecnologia.

E quais seriam os padrões envolvidos na modernização que produziram mudanças no status de pecuarista pantaneiro? Para identificarmos estes padrões, um caminho produtivo é entender como a modernização se realiza enquanto uma dinâmica social de mudança. Sociologicamente, denominamos à " interação repetitiva de padrões de comportamento comumente encontrados na vida social" (HORTON \& HUNT, 1980, p. 251) de processos sociais. A classificação mais frequente dos principais processos sociais ocorre em termos de cooperação, competição, conflito, acomodação e outros. Tais processos ocorrem tanto no nível individual quanto no nível grupal.

As transformações que identificamos na ocupação de pecuarista pantaneiro podem ser classificadas dentro do que Lenski chama de mudanças cumulativas, ou seja, associadas a sistemas compostos de múltiplas partes interrelacionadas. Dentro desse sistema, algumas partes mudam enquanto outras permanecem como estavam. Assim, a mudança cumulativa é um processo que 
combina elementos de continuidade com elementos de mudança. Muitas partes do sistema são preservadas por extensos períodos enquanto novas parte são adicionadas e outras partes são substituídas e transformadas (LENSKI, 2005).

Durante um tempo, o status de pecuarista pantaneiro gozou de elevado prestígio nas sociedades mato-grossense e poconeana e chegou a imprimir culturalmente um estilo de vida, chamado de pantaneiro, que combinava valores religiosos católicos, estratificação social baseada em grande desigualdade social em que o pecuarista ocupava o topo da hierarquia, grandes propriedades para criação de gado, nas quais viviam a família nuclear do pecuarista e de seus empregados, e baixa produtividade.

Esta estrutura social, aqui entendida como o conjunto de status sociais vinculados ao status de pecuarista pantaneiro e os sistemas de cultura aos quais ele estava e está ligado (MARTIN, 2009; TURNER, 2000) vem sofrendo transformações. As variáveis explicativas que identificamos como possíveis variáveis independentes relacionam-se com o que a literatura sociológica denomina de modernização.

Segundo Sztompka, a noção de modernização pode ser considerada em três sentidos distintos: (1) sinônimo de mudança social "progressiva de qualquer natureza em que a sociedade se move para frente ao largo de alguma escala de aperfeiçoamento aceita" (SZTOMPKA, 1998, p. 227); (2) Invoca a ideia de "modernidade", expressa no complexo de transformações sociais, políticas, econômicas, culturais e mentais que ocorreram no ocidente a partir do século $\mathrm{XVI}$, atingindo seu apogeu nos séculos XIX e XX. Refere-se aos processos de industrialização, urbanização, racionalização, burocratização, democratização, ascensão do capitalismo, disseminação do individualismo e da motivação para as realizações, afirmação da razão e da ciência, entre outros (SZTOMPKA, 1998, p. 227); (3) em um sentido particular, refere-se apenas aos processos sociais de mudança social experimentados por sociedades consideradas "atrasadas" ou "subdesenvolvidas" e "seus esforços para alcançar os países avançados, ou mais desenvolvidos, que com eles coexistem no mesmo período histórico dentro da sociedade global (SZTOMPKA, 1998, p. 228).

No sentido que adotamos aqui, no nível micro e macrossociológico da estrutura ocupacional de pecuarista pantaneiro, significa o fenômeno individual e social pelo qual passam pecuaristas e seus status ocupacionais de uma estrutura social tradicional ou pouco desenvolvida tecnologicamente para atitudes racionais social e economicamente e estruturas sociais fortemente diferenciadas.

Embora disseminada na literatura sociológica e econômica, a ideia de modernização tem sido questionada em sua dimensão empírica como contrária às evidências históricas, e em sua dimensão teórica como baseada em pressupostos não sustentáveis (SZTOMPKA, 1998).

$\mathrm{Na}$ verdade, as críticas são mais baseadas em objeções extra científicas do que científicas. Na dimensão empírica, dizia-se que os esforços modernizadores quase nunca produziam os resultados prometidos. Há aqui uma confusão entre a sociologia enquanto ciência e engenharia social. A teoria da modernização tem alguns pressupostos, se eles se realizam ou não entram na 
dimensão do seu questionamento enquanto teoria e não seu questionamento enquanto engenharia social. Enquanto teoria que se pretende científica é probabilística.

No plano sócio psicológico, a crítica é que a modernização provoca efeitos colaterais patológicos. A destruição de instituições e modos de vida tradicionais produziram, em diversos casos, a desorganização social e a anomia, conforme aponta Eisenstadt (1968). Neste caso, como na dimensão empírica, a modernização é teorizada como uma transformação exclusivamente positiva, o que é contrário ao que sociologia da mudança social defende, conforme Lenski (2005).

Na dimensão teórica, os pressupostos evolucionistas subjacentes foram considerados inaceitáveis. Aqui estamos, mais uma vez, diante de objeções extra científicas. Uma normatização epistemológica. $O$ que torna um pressuposto aceitável ou não é sua operacionalização e sustentação empírica. Mas, existe também questionamentos relevantes. A crítica de que a estrutura teórica deveria incorporar variáveis do contexto global e de causação endógena. Tal crítica foi considerada por Tiraykian (1985) em meados dos anos 1980, quando assistimos a um renascimento da teoria da modernização.

\section{TORNANDO-SE MODERNO OU IMPACTOS DA MODERNIZAÇÃO SOBRE ESTRUTURAS SOCIAIS}

Inkeles \& Smith (1981) executaram um estudo comparativo que combinou as dimensões micro e macrossociológica e que corrige o que os críticos chamavam de concepção etnocêntrica e ocidentalista dos objetivos da modernização por se basear na ideia de que muitas sociedades e Estados Modernos "ou em processo de modernização se desenvolveram em outra direção que não a dos Estados-Nação europeus" (EISENSTADT apud SZTOMPKA, 1998).

O enfoque sócio psicológico de Inkeles \& Smith considera a modernização basicamente como um processo de mudança "na maneira de perceber, expressar e avaliar. O moderno é definido como um modo de funcionamento individual, um conjunto de disposições para agir de determinada maneira" (INKELES \& SMITH, 1981, p. 16). Dessa forma, o que se denomina de moderno não está ligado a uma época ou a um lugar determinado do que qualquer definição de modernidade se pensamos em termos de arranjos estruturais, "se modernidade é definida como um estado de espírito, as mesmas condições devem ter estado presentes na Inglaterra da Rainha Elizabeth, na Grécia de Péricles, e no Japão de Tokugawa” (INKELES \& SMITH, 1981, p. 16).

Para que sua concepção de modernidade individual não fosse acusada de ser baseada em padrões de valores europeus, Inkeles \& Smith formularam um desenho de pesquisa intercultural, realizado simultaneamente na Ásia, África e América do Sul.

Embora o modelo analítico de Inkeles \& Smith (1981) representasse um ponto de vista teórico, ele não ignora o que diversos estudos empíricos 
apontavam como proposições sobre as prováveis maneiras com que a modernização está ligada às diversas atitudes em relação "à religião, família, estratificação social e muitas outras" (INKELES \& SMITH,1981, p. 24).

$\mathrm{Na}$ estrutura social que se desenha a partir do status ocupacional de pecuarista pantaneiro, a religião, a família e a estratificação social tem contornos bem definidos e diferentes daqueles que a modernização traz em seu bojo.

Conforme já mencionamos, o pecuarista pantaneiro era religiosamente católico. Grande patrocinador das festas de santo, cujas realizações envolvia a doação de recursos e gado, momento em que reafirmava seu prestígio e sua posição na hierarquia social.

Em relação à família, vivia quase isolado nas fazendas, com família numerosa e estreita relação com as famílias dos empregados, embora a hierarquia fosse claramente demarcada. A participação feminina majoritariamente estava restrita ao espaço doméstico.

E em relação à estratificação social, viviam em uma sociedade em que eles ocupavam o topo da hierarquia. Os pecuaristas participavam ativamente da vida política no município e no Estado. Uma ilustração de como isto se manifestava na sociedade poconeana, é o fato de que em Poconé existiam clubes reservados aos filhos dos pecuaristas pantaneiros.

Blau \& Duncan (1967) nos mostraram, de certa forma, como o impacto da modernização repercute na estratificação social, quando pensamos na mudança das aspirações educacionais e ocupacionais dos membros de estruturas sociais de ocupações vinculadas ao campo, por exemplo, no caso, os fazendeiros. Eles mostram que tende a diminuir o número de pessoas vivendo em fazendas, vivendo a vida na agricultura e buscando ocupações rurais.

Uma das razões que eles apresentam para explicar esta redução de ocupações no campo é que, com a mecanização, o avanço tecnológico, um número bem menor de trabalhadores pode produzir o mesmo volume de produtos que antes era produzido. $E$ isto tende a mudar a dinâmica social de recrutamento para as ocupações no campo de uma geração para outra. Blau \& Duncan (1967) mostram que os fazendeiros eram desproporcionalmente recrutados em sua própria classe e de trabalhadores ligados a ocupações rurais. $E$ que em 1962, 1/4 dos homens que compunham a força de trabalho de 12 milhões investigada, tinham pais que eram fazendeiros, administradores de fazendas ou trabalhadores de fazendas. Isto nos mostra que o background de fazendeiros se alimentava, basicamente de sua própria classe e atividades afins e, ao mesmo tempo, era uma variável importante para entender a origem e 0 destino dos indivíduos, quando pensamos processo social de mobilidade social.

Voltando às repercussões da modernização nas várias esferas da vida social, Inkeles \& Smith (1981) nos mostram que o impacto da modernização nas três esferas mencionadas acima, caso estejam presente na estrutura da sociedade poconeana, tendem a provocar transformações que provavelmente repercutirão no status de pecuarista pantaneiro.

Religião e família no sentido em que descrevemos na estrutura social da tradicional sociedade poconeana, constituem obstáculos ao processo de modernização, pois, como advertiu Moore, geralmente a estrutura familiar 
tradicional constitui uma barreira contra o desenvolvimento industrial, pois encoraja que o indivíduo tenha mais confiança na sua segurança do que nos seus dispositivos (MOORE, 1965).

A literatura sobre modernização indica que, como um fenômeno atrelado ao urbanismo e à industrialização, tende a enfraquecer o vigor das extensas relações familiares. Não pudemos aquilatar a relação destas duas variáveis independentes com a estrutura social dos pecuaristas pantaneiros, considerada variável dependente. Embora possamos falar de um processo de urbanização, não há sinais de industrialização em um município que continua a ser fundamentalmente rural no sentido de suas atividades econômicas fundamentais, agricultura, pecuária, em alguma medida o turismo, mas que não interage com a cidade diretamente, e a mineração que se desenvolve de uma maneira que não podemos considerar significativamente industrial.

A literatura sociológica referente aos impactos da modernização sobre a estrutura social da família indica que as variáveis sociais independentes fundamentais se relacionam com as mudanças nas aspirações educacionais e ocupacionais. Na medida em que atinge a mulher, juntamente com os procedimentos de controle de natalidade, tende a influenciar o tamanho da família. E, na medida em que atingem os filhos, estes não estarão mais dispostos a serem parceiros dos pais no trabalho na fazenda, pois terão outras aspirações educacionais e ocupacionais.

Em relação à religião, como as grandes famílias, ela também se coloca como obstáculo ao desenvolvimento econômico e como tal vítima do processo de modernização. Vários estudos que chegavam a Weber, indicavam que a religião pode ser o principal obstáculo à modernização, por se constituir frequentemente "no baluarte das tradições e no repositório de crenças e valores incompatíveis com a ciência moderna, com a tecnologia e com a ideia de progresso" (INKELES \& SMITH,1981, p. 26).

Nos surveys que aplicamos, não coletamos dados sobre a religião, embora saibamos da forte religiosidade da geração mais antiga de pecuaristas pantaneiros. Como entrevistamos a maior parte de nossa amostra em suas residências, era frequente nos depararmos com seus símbolos religiosos, geralmente nas salas de estar de suas casas, quando não interrompíamos momentos de oração. Mas não mensuramos o quanto essa religiosidade difere entre as diferentes gerações de pecuaristas, entre os pecuaristas pantaneiros que residem em Poconé e os que não residem, entre aqueles que são nascidos em Poconé e aqueles que são de fora do município, entre aqueles que são de Poconé, mas que estudaram fora de Poconé (curso médio e/ou superior) e aqueles que fizeram toda a sua escolarização no município.

\section{MÉTODO}

Iniciamos a pesquisa em agosto de 2013. Formulamos 15 questões não estruturadas e aplicamos a 5 pecuaristas de Poconé. A partir de informantes nascidos no município de Poconé, mas que residem na capital do Estado e, por intermédio da Sindicato Rural de Poconé, elegemos estes potenciais entrevistados. As cinco entrevistas não estruturadas nos forneceram informações, como as questões mais importantes no que se referia às 
dificuldades da ocupação de pecuarista pantaneiro e algumas categorias importantes, bem como os assuntos delicados e situações a serem evitadas.

Com estas informações, formulamos um questionário estruturado e 0 testamos em quatro outros pecuaristas. Ao final desse processo, elaboramos finalmente nosso instrumento, um questionário com 40 questões, divididas em 3 blocos. Um primeiro, em que fazíamos uma introdução, abordando questões mais neutras, um segundo em que fizemos as questões que sustentam nossas hipóteses a respeito da ocupação de pecuarista pantaneiro e um terceiro bloco em que coletamos dados sobre seu perfil sócio demográfico.

Em função das dificuldades de acesso ao pantanal, pois existem áreas acessíveis apenas de avião e outras apenas com veículos apropriados, desenhamos nossa amostra pelas vias de acesso, como uma amostra por conglomerados. Estipulamos 4 vias de acesso: Estrada Parque Transpantaneira; Estrada Poconé-Porto Cercado; Estrada do Boqueirão e Rodovia PoconéCuiabá. Por estas estradas se alcançam as estradas vicinais.

Entrevistamos 28 pecuaristas. Segundo o posto do Indea em Poconé, existem 2113 propriedades no município, 1556 na terra firme e 557 no pantanal. Sabemos que no baixo pantanal existem muitas propriedades abandonadas e que algumas propriedades têm sido adquiridas por um mesmo proprietário, o que pode indicar que talvez exista um número menor de propriedades, mas nem o Indea, nem a prefeitura nem o Sindicato Rural souberam informar com precisão.

Depois da coleta de dados via entrevistas não estruturadas e de testar o questionário desenhado, iniciamos sua aplicação em 2014 e o finalizamos em março de 2015.

\section{RESULTADOS}

O status ocupacional de pecuarista pantaneiro continua a ser exclusivamente desempenhado por homens. Não entrevistamos nenhuma mulher e não soubemos de nenhuma pecuarista pantaneira em Poconé.

Em relação à escolaridade:

Tabela 1: Escolaridade dos Pecuaristas de Poconé-MT

\begin{tabular}{l|c|c}
\hline Nível escolaridade & Quantidade & Percentagem \\
\hline Superior & 15 & $53,50 \%$ \\
\hline Ensino Médio & 13 & $46,50 \%$ \\
\hline
\end{tabular}

Fonte: Elaboração própria

Em relação a desenvolver ou não outras atividades econômicas:

Desenvolve outras atividades econômicas? 
Tabela 2: Atividades econômicas

\begin{tabular}{l|c|c}
\hline $\begin{array}{c}\text { Outras atividades } \\
\text { econômicas? }\end{array}$ & Quantidade & Percentagem \\
\hline $\mathrm{Sim}$ & 21 & $75 \%$ \\
\hline $\mathrm{Não}$ & 7 & $25 \%$ \\
\hline
\end{tabular}

Fonte: Elaboração própria

Entre aqueles que disseram não desenvolver outra atividade econômica, alguns sublinhavam que não desenvolviam naquele momento. Geralmente eram pecuarista comais de 60 anos que já tinha se aposentado de sua outra atividade. Para conhecer, entre aqueles que desenvolvem outras atividades econômicas, quais as principais atividades por eles desenvolvidas, perguntamos:

Tabela 2a: Pecuaristas Pantaneiros que desenvolvem outra atividade econômica

\begin{tabular}{l|c}
\hline Qual a outra atividade econômica & Quantidade \\
\hline Agricultura & 1 \\
\hline Turismo & 3 \\
\hline Prestador de Serviços & 2 \\
\hline Comércio & 9 \\
\hline Profissional Liberal & 2 \\
\hline Indústria & 1 \\
\hline Funcionário Público & 3 \\
\hline Total & $\mathbf{2 1}$ \\
\hline
\end{tabular}

Fonte: Elaboração própria

Qual das atividades econômicas é a principal, a pecuária ou a outra?

Tabela 2b: Atividade econômica principal

\begin{tabular}{l|c}
\hline Atividade econômica & Proporção \\
\hline Pecuária & $23,80 \%$ \\
\hline A outra atividade & $76,20 \%$ \\
\hline
\end{tabular}

Fonte: Elaboração própria.

É possível viver exclusivamente da pecuária no pantanal hoje? Muitos que responderam sim e aqueles que também responderam não, estipulavam as condições que tornam a pecuária viável no pantanal hoje: tamanho mínimo da propriedade e a quantidade mínima de cabeças de gado. 
Tabela 3: Vivem exclusivamente da pecuária

\begin{tabular}{l|l}
\hline Exclusivamente & Proporção \\
\hline Sim & $21,50 \%$ \\
\hline Não & $78,50 \%$ \\
\hline
\end{tabular}

Fonte: Elaboração própria.

Podemos dizer que entrevistamos quatro pecuaristas da nova geração, embora na fase de coleta de dados inicial e na fase de testes, entrevistamos outros quatro. Eles se destacam por defender claramente que a pecuária no pantanal só é viável enquanto atividade econômica complementar, por defender uma pecuária mais empresarial e por criticarem a insistência da velha geração em acreditar que a pecuária pantaneira extensiva de outrora ainda seja viável.

Tabela 4: Faixa etária dos pecuaristas pantaneiros

\begin{tabular}{l|c}
\hline Faixa Etária & Quantidade \\
\hline $30-40$ & 2 \\
\hline $40-50$ & 2 \\
\hline $50-60$ & 14 \\
\hline $60-70$ & 5 \\
\hline $70-80$ & 5 \\
\hline
\end{tabular}

Fonte: Elaboração própria.

A estrutura de produção da pecuária pantaneira era basicamente familiar, baseada na grande propriedade e na pecuária extensiva. Neste cenário, a ajuda dos filhos era fundamental, que posteriormente assumiam a fazenda.

Filhos ajudam na fazenda?

Tabela 5: Proporção de pecuaristas pantaneiros que contam com a ajuda dos filhos

\begin{tabular}{l|c}
\hline Contam com a ajuda dos filhos & Proporção \\
\hline Sim & $32,14 \%$ \\
\hline Não & $67,85 \%$ \\
\hline
\end{tabular}

Fonte: Elaboração própria.

Deve-se levar em consideração que entre aqueles que disseram não, alguns tem filhos pequenos e, portanto, sem condições ainda de ajudarem na fazenda. E entre aqueles que ajudam, 2 ou 3 são médicos veterinários, ou seja, desempenham ocupações ligadas à pecuária. Mas, se eles ajudam, eles também trabalham fora, ou seja, a ajuda é uma ajuda mesmo. 
Tabela 6: Ocupação do Pai

\begin{tabular}{l|c}
\hline Ocupação do Pai & Proporção \\
\hline Pecuarista & $71,42 \%$ \\
\hline Não Pecuarista & $28,58 \%$ \\
\hline
\end{tabular}

Fonte: Elaboração própria.

É importante ressaltar que entre aqueles que não têm pais pecuaristas, alguns tornaram-se pecuaristas porque a esposa é filha de pecuaristas e herdou a terra.

\section{Tabela 7: Distinção de Não-Pecuaristas}

\begin{tabular}{l|c}
\hline Status ocupacionais & Proporção \\
\hline Status ocupacionais rurais & $50 \%$ \\
\hline Status ocupacionais urbanos & $50 \%$ \\
\hline
\end{tabular}

Fonte: Elaboração própria.

\section{DISCUSSÃO E CONCLUSÃO}

É possível visualizar a mudança que experimenta a estrutura social da sociedade poconeana por intermédio de uma visita à cidade. Expressão e símbolo de poder que os pecuaristas pantaneiros não têm mais, a cidade tenta encontrar outras vocações econômicas e, conforme o conceito de mudança cumulativa de Lenski (2005), expressa continuidades e descontinuidades em relação a um tempo em que os pecuaristas pantaneiros eram os atores sociais fundamentais no que se refere ao aspecto econômico, político e social.

Em relação à tabela 1 , não controlamos a variável escolaridade e, portanto, não sabemos como ela se relaciona com as mudanças no status de pecuarista pantaneiro. A geração mais nova faz uma distinção entre ser fazendeiro e ser pecuarista no pantanal hoje. Eles dizem que os mais velhos são fazendeiros, ou seja, querem fazer de tudo, mas são pouco especializados e não sabem administrar a fazenda de uma maneira empresarial, condição importante, segundos os mais novos, para que a pecuária pantaneira possa se tornar viável. Apresentam a pecuária na terra firme e o agronegócio como modelos bemsucedidos a serem seguidos. Nesse sentido, eles tendem a minimizar as críticas às exigências ambientais do poder público e tendem a enfatizar a não viabilidade da pecuária enquanto atividade econômica exclusiva (tabela 3).

Os pecuaristas mais velhos, exemplificados aqui, fundamentalmente, por aqueles que têm quase 60 anos ou mais, tendem a se prender mais ao passado, ao modelo de pecuária extensiva que dava certo e a serem críticos da legislação ambiental e trabalhista que inviabilizam, de certa forma o modelo antigo.

A tabela 2 expressa mudança significativa no status ocupacional de pecuarista pantaneiro. Embora no passado ele participasse da vida pública, em função de seu elevado prestígio, o que o levava a patrocinar festas de santo, 
com significativos recursos, e fosse influente na vida política de Poconé e de Mato Grosso, o status ocupacional de pecuarista pantaneiro era seu status principal, todos os outros gravitavam em torno dele. Mas isto mudou e vem mudando, conforme mostra a tabela 2. Sete pecuaristas têm a pecuária como sua única atividade econômica. E, conforme sublinhamos, alguns porque já estão aposentados de sua outra atividade econômica. Nesse sentido, a tabela tende a expressar o pensamento da geração mais nova, que vê na pecuária pantaneira um status ocupacional complementar e não exclusivo.

Podemos dizer que estamos diante de uma consequência da modernização? Parece que sim, mas isto deve ser melhor investigado. A dinâmica social de divisão familiar das grandes propriedades, provavelmente é uma variável importante. Com propriedades menores, a estrutura de produção baseada na família, grande propriedade e pecuária extensiva tornou-se inviável. O tamanho bem menor da propriedade, a redução significativa no tamanho do rebanho e os atrativos em termos de aspirações educacionais e ocupacionais oferecidos pela capital, distante 100 quilômetros de Poconé, fizeram com que a grande maioria dos filhos dos pecuaristas desistisse da vida na fazenda. A tabela 5 nos fornece pistas nesse sentido. Os próprios pecuaristas pantaneiros expressavam suas preocupações, durante as entrevistas, em relação ao futuro das suas propriedades, pois os filhos não se interessam por elas.

Em relação à tabela $2 a$, é importante destacar a presença de pecuaristas no comércio, enquanto profissionais liberais e no turismo. E necessário mais investigações, mas parece-nos que os pecuaristas antigos também exerciam atividades econômicas no comércio como uma atividade econômica secundária, que provavelmente era exercida por um de seus filhos ou parentes, mas hoje ela passa a ter um peso maior e a ser exercida por ele mesmo ou por ele e sua mulher ou pela mulher. Aliás, o papel da esposa na pecuária pantaneira merece ser melhor investigado. Ela participava ativamente seja diretamente, seja indiretamente, mas sua participação não é reconhecida. Tentei entrevistar algumas mulheres que estavam à frente dos negócios em função do adoecimento de seus maridos, mas elas se recusaram, afirmando que embora fossem parceiras (muitas inclusive opinavam durante as entrevistas), falar de pecuária era assunto dos maridos.

Para aqueles que são profissionais liberais, o status de pecuarista pantaneiro passa a ser uma atividade de fim de semana e um projeto para 0 futuro, após a aposentadoria.

Para aqueles que trabalham com o turismo, a pecuária constitui-se em uma atividade afim, pois o status de pecuarista está atrelado ao status de proprietário de pousada.

Em relação à tabela 6, os dados sustentam o que Blau \& Duncan (1967) apontavam nos anos de1960 nos EUA. Os ocupantes do status de pecuaristas pantaneiros são desproporcionalmente recrutados de sua própria classe e de trabalhadores ligados a ocupações rurais.

Conforme apontamos, entre aqueles que os pais não são pecuaristas, alguns se casaram com mulheres filhas de pecuaristas pantaneiros e herdaram suas terras. Com as dificuldades econômicas enfrentadas pelos pecuaristas 
pantaneiros, a nova geração tem buscado status ocupacionais urbanos, conforme atestamos quando perguntávamos o que seus filhos faziam.

Muitas propriedades têm sido adquiridas por empresários de fora de Mato Grosso, que tem uma relação diferente com o status de pecuarista pantaneiro.

As mudanças que identificamos merecem ser melhor investigadas, com uma pesquisa complementar que focalize mais precisamente a estrutura social ocupacional de Poconé e o percurso ocupacional que fez o pecuarista pantaneiro e sua esposa e que estão fazendo seus filhos.

\section{REFERÊNCIAS BIBLIOGRÁFICAS}

BLAU, P. \& DUNCAN, O.D. The American Occupational Structure, New York: The Free Press, 1967.

EISENSTADT, S. N. Modernização e Mudança Social. Belo Horizonte: Editora do Professor, 1968.

HORTON, P. B. \& HUNT, C. L. Sociologia. São Paulo: McGraw-Hill, 1980.

INKELES, A. \& SMITH, D. H. Tornando-se Moderno: as transformações individuais ocorridas em seis países em desenvolvimento. Brasília: Editora UnB, 1981.

LENSKI, G. Power and Privilege. New York: McGraw-Hill, 1966.

LENSKI, G. History and Social Change. American Journal of Sociology. No 82. pp. 548-564,1976.

LENSKI, G. Ecological-Evolutionary Theory: principles and applications. Boulder: Paradigm Publishers, 2005.

LENSKI, G. \& LENSKI, J. Human Societies. New York: McGraw-Hill, 1974.

MARTIN, J. L. Social Structures. Princenton: Princenton University Press, 2009.

MOORE, W. E. Industrialization and Labor: social aspects of economic development. New York: Russell and Russell, 1965.

SZTOMPKA, P. A Sociologia da Mudança Social. Rio de Janeiro: Civilização Brasileira, 1998.

TIRYAKIAN, E. A. The Changing Centers of Modernity. In: E. Cohen; M. Lissak e U. Almagor (eds.), Compartive Social Dynamics. pp. 131-147.Boulder: Westview Press, 1985.

TURNER, J. H. Sociologia - conceitos e aplicações. São Paulo: Makron Books, 2000. 